\section{Military Technical College Kobry El-Kobbah, Cairo, Egypt}

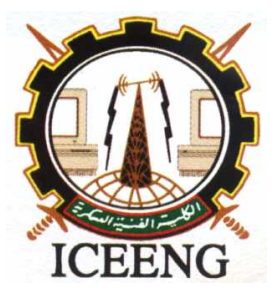

\author{
$6^{\text {th }}$ International Conference \\ on Electrical Engineering \\ ICEENG 2008
}

\title{
Sensor-actuator system with orthogonal magnetic fields
}

\author{
By \\ Adrian Baraboi* \\ Maricel Adam* \\ Catalin Pancu *
}

\section{$\underline{\text { Abstract: }}$}

The disconnecting of circuit breakers to overload and short-circuit current is made using an electromagnetic and thermal breaking devices. Each type of circuit breaker, which it rates current, has a sensor-actuator system for protection. In this order, we have a lot of variants for sensor-actuator systems. The paper reports a possibility to eliminate this inconvenient. In this order, we propose a sensor actuator system with orthogonal magnetic field, which may be applied for all type of circuit breakers. The principle of proposed system consists of minimal voltage breaking systems with orthogonal magnetization. The practical solution of proposed method consists of experimental sensor-actuator system and it is under romanian patent.

\section{Keywords:}

Circuit breaker, sensor-actuator, orthogonal magnetization

* “Gh. Asachi” TU of Iasi, Romania 


\section{Introduction:}

Low Voltage (LV) automatic circuit breakers are switchgears with or without contacts, having nominal voltages till $1000 \mathrm{~V}$ in $\mathrm{AC}$ and till $1200 \mathrm{~V}$ in DC, capable to establish, to maintain and to breaking normal and short circuit currents. In additional with switching function, LV automatic circuit breakers ensure the protection of the installation where are placed, in this purpose being equipped with releasers sensitive at overcurrents, at diminution of supply voltage etc.

Figure 1 shows the component elements of a LV automatic circuit breakers of disjunctor type: 1-terminals, 2- magnetic blow, 3- auxiliary contacts, 4-main contacts, 5- maximal current releasers, 6- minimal voltage releaser, 7-electromagnet, 8-operating mechanism, 9- handle operating, 10- lock.

LV automatic circuit breakers are designed with maximal current releasers which realises the installation protection at overload and short-circuit currents. From this point of view it is interesting to know the time-current protection characteristic, curve that establish, for specified operating conditions, the dependence between the operating time, $t_{a}$, of the circuit breaker al symmetrical presumed current (RMS). This characteristic is adjustable, its shape being presented in Figure (1) b, c.

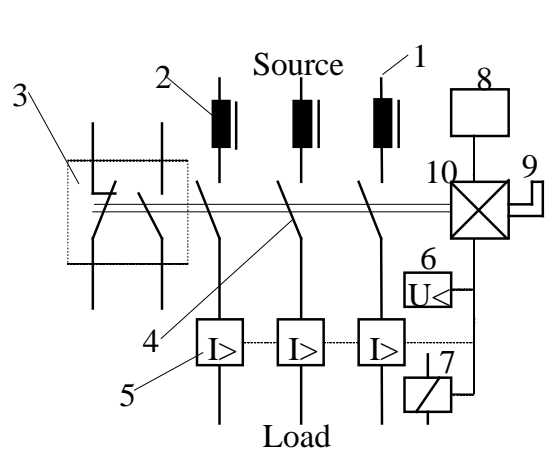

$\mathrm{a}$

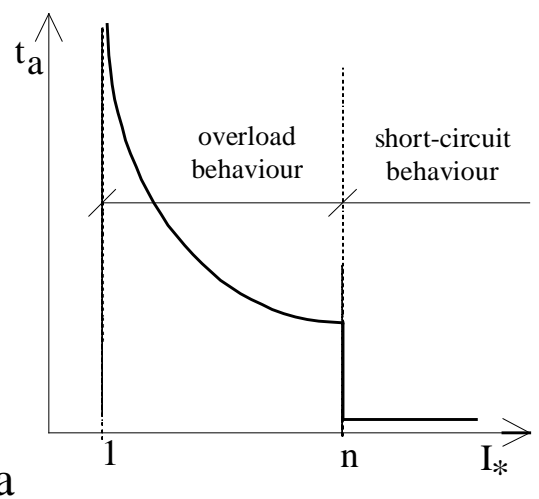

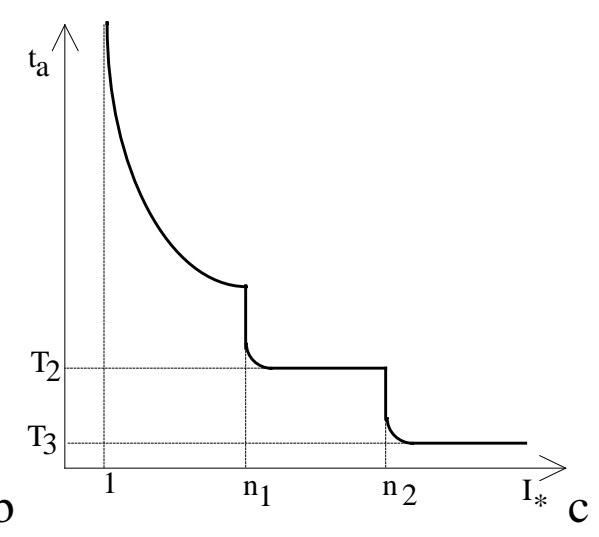

Figure (1): LV automatic circuit breakers: a-principle scheme; $b$, c- tipical protection characteristics, time-current

\section{Magnetisation in orthogonal fields:}

The orthogonal magnetising controlled reactor (CROMAG), working based on the "Procopiu effect", is an electrical apparatus that has the iron core actuating in two or more across magnetic fields, produced by windings or other magneto motive force sources (permanent magnets), perpendicularly placed. 
Generally (Figure 2a), on one of the two orthogonal directions of magnetisation operate the main magnetic field, $\overline{\mathrm{H}}$ and on other, the controlling magnetic field, $\overline{\mathrm{H}}_{\mathrm{c}}$ [9]. With this end in view, the core of a CROMAG has a special form, cylinder or cylinder envelope, for example. As shown in Figure 2b, the CROMAG consists of three main parts: 1-the cylindrical magnetic core, 2-the coil winding, 3-the control winding.

The CROMAG has some interesting applications in the domain of linear and non-linear electromagnetic driving devices, power systems [4], [7], [11] or weak power systems [2], [3], [9], [12]. A recent application has in view the using of the CROMAG in the construction of the network filters, associated to the HDVC installations, [7]. If the CROMAG operates at high voltage, between the excitation and the control voltages is necessary to introduces an electro-insulation device, 4, Figure (2c). In the most general case, the CROMAG has the characteristics of the non-linear and parametric coil. Used as an inductive element in the oscillating circuits, the CROMAG leads to the install, in forced state, of some phenomena of the non-linear multiple resonance.

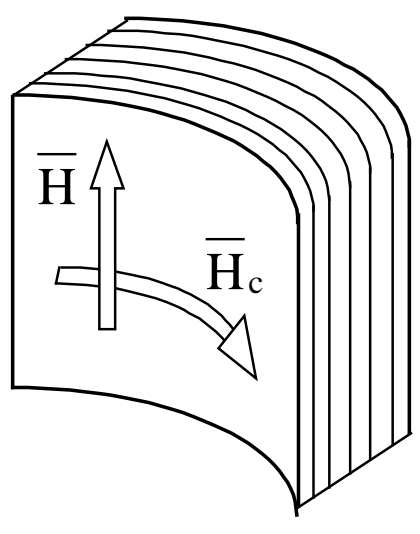

a

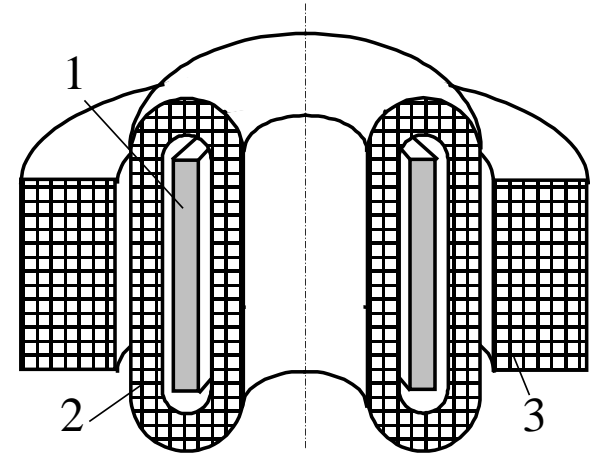

b

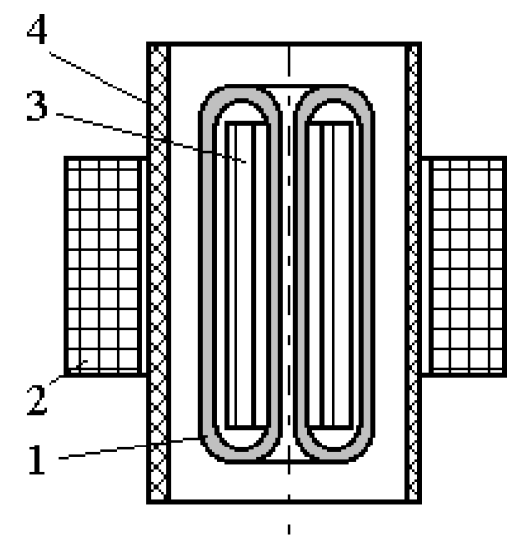

C

Figure (2): Orthogonal magnetising: a-phenomena illustration; b-CROMAG design; $c$ CROMAG construction: 1-magnetic core, 2-DC control coil, 3-AC coil

The CROMAG characteristics are of the shape $\theta\left(\psi, \psi_{c}\right), \theta_{c}\left(\psi, \psi_{c}\right)$, where $\left(\theta, \theta_{c}\right)$ and $\left(\psi, \psi_{c}\right)$ are the magnetomotive forces and excitation and control magnetic fluxes, respectively, [5]. These can be analytical explained under the simplified shape through the expressions:

$$
\left.\begin{array}{l}
\theta=b_{10} \psi+b_{12} \psi \psi_{c}^{2}+b_{30} \psi^{3}, \\
\theta_{c}=b_{10}^{c} \psi_{c}+b_{12}^{c} \psi_{c} \psi^{2}+b_{30}^{c} \psi_{c}^{3},
\end{array}\right\}
$$


$\mathrm{b}_{\mathrm{pq}}, \mathrm{b}_{\mathrm{pq}}^{\mathrm{c}}$ being known. The model of a CROMAG has at the base the equivalent electrical scheme of a coil with ferromagnetic core, [1]. In Figure (3) is given the equivalent circuit, realised in ATP Draw subroutine, of simulation in EMTP of the CROMAG characteristics (Figure $3 b$ ). The circuit elements $R, R_{p}, L_{d}$ and $L_{n}$ represents the CROMAG parameters, respective the resistance of the excitation winding, the resistance equivalent with the active losses in iron, the dispersion inductance and the non-linear inductance. The control circuit intervenes through the PARAM block.

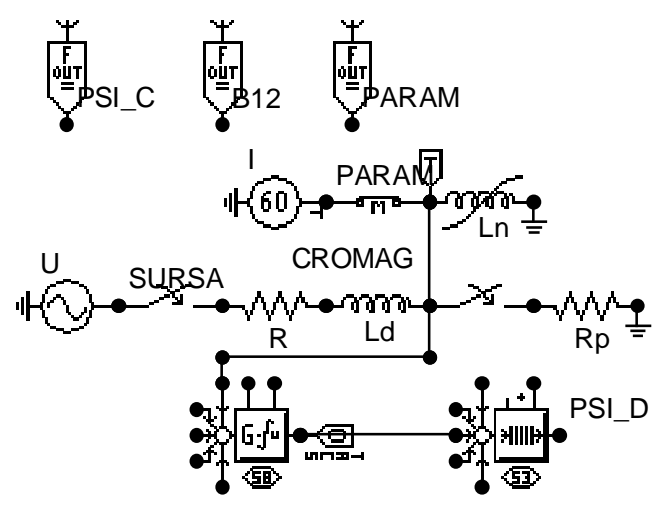

a

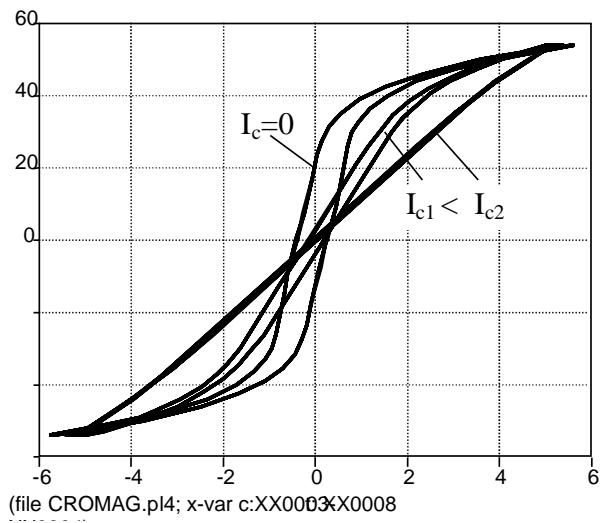

b

Figure (3): a-ATP Draw simulating circuit for CROMAG; b-CROMAG flux-current EMTP simulating characteristics $\theta(\psi)$

\section{Sensor-actuator with CROMAG:}

All categories of electromagnets can be equipped, in principle, with a local orthogonal magnetised control, some of them allowing the magnetisation of the entire volume. Figure 4a presents an electromagnet of clack type, where the magnetic flux of excitation is made by the winding 1 , while the magnetic flux of control by the winding 2 .

The orthogonal control can be modelled with a reluctance in the scheme of magnetic circuit, which controls the actuator operating. 

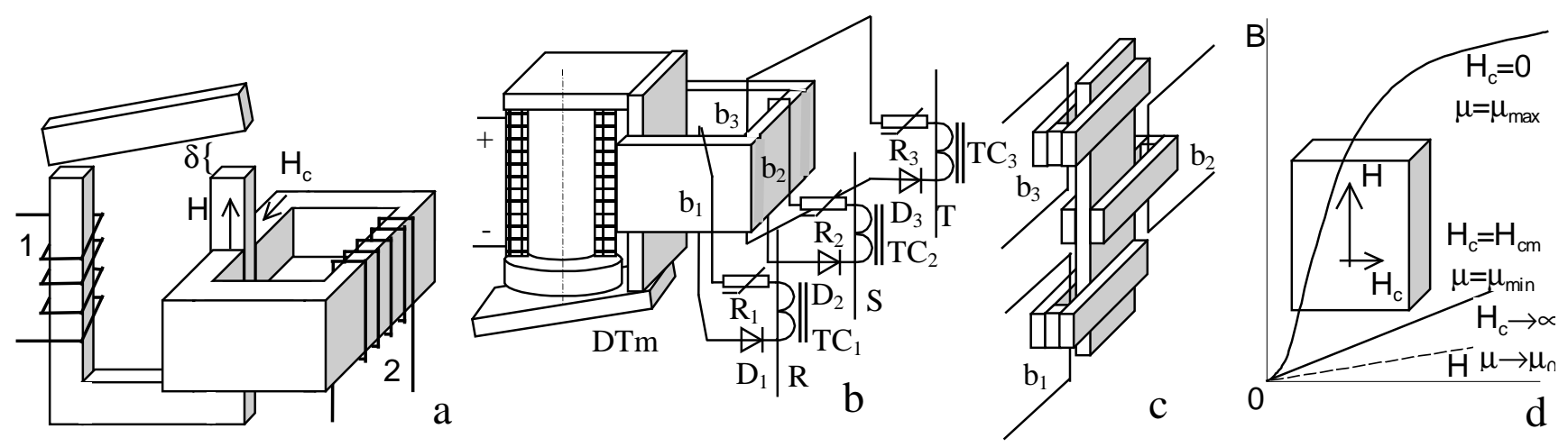

Figure (4): a-Principle of orthogonal control of an electromagnet; minimal voltage releaser: b-with unique ferromagnetic core; $c$-with three-phases magnetic circuit; $d$ - magnetisation characteristics
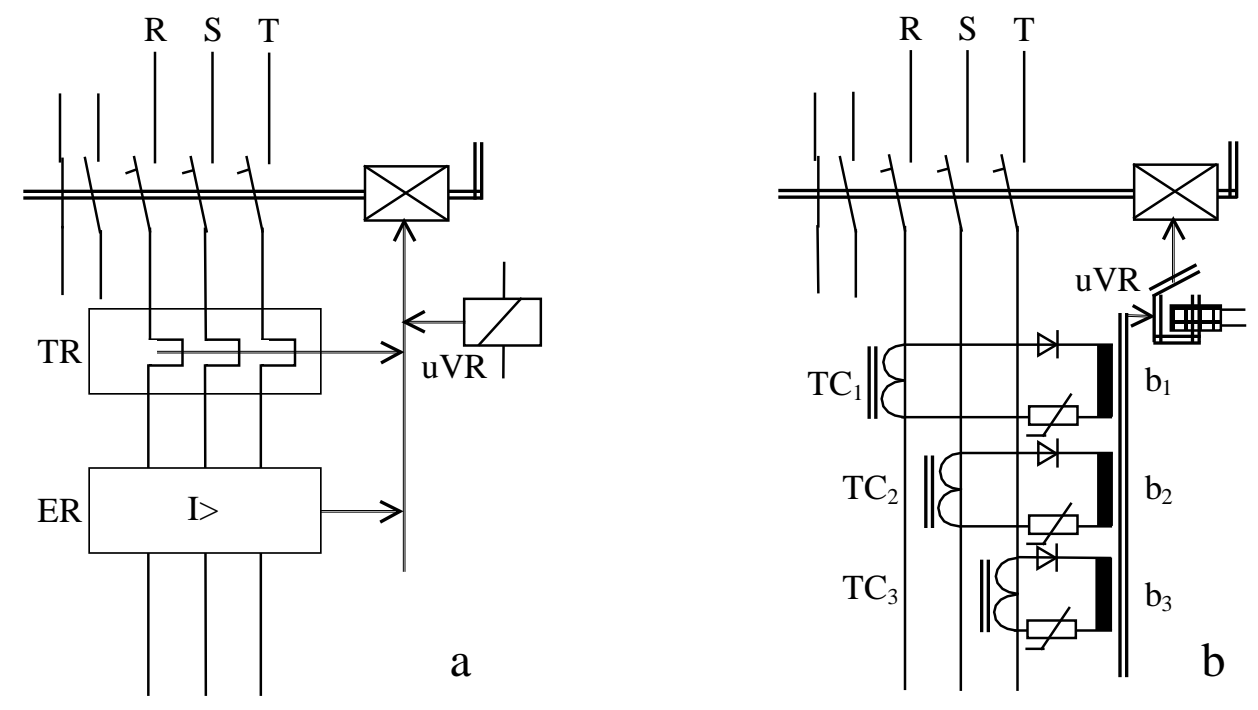

Figure (5): Electrical scheme of a LV automatic circuit breakers: $a$-with conventional $u V R ; b$-with $u V R$ orthogonal controlled

The releaser is of uVR type (of minimum voltage) and operates orthogonal controlled through a magnetic field, generated by a rectified currents system (Figure 5b).

The under voltage releaser $\mathrm{uVR}$ is an electromagnet of clack type with economiser resistance, which includes (Figure 5b) a magnetic circuit with three coils (b1, b2, b3) or is realised from three magnetic circuits, one for each coil, how it can see in Figure $5 b$.

Coils supply $\mathrm{b}_{1}, \ldots \mathrm{b}_{3}$ it realises from current transformers $\mathrm{TC}_{1}, \ldots \mathrm{TC}_{3}$, connected on each phase in part, with rectified current of a diode and an adjustable delay element, for example, a non-linear resistance of varistor type. 
uVR releaser controls the circuit breaker interruption at variation of supply voltage operating in given conditions as under voltage releaser and also, at overcurrents, operating with orthogonal control. In this sense, rotating the magnetisation characteristic $\mathrm{B}(\mathrm{H})$ in the sense of decreasing of magnetic permeability, Figure (3b), it obtains the decreasing of active force developed by the electromagnet, till the determination of circuit breaker interruption.

Figure 5a shows the electrical scheme of a usually circuit breaker equipped with conventional under voltage releaser $\mathrm{UVR}$ and with thermal releasers TR, and electromagnetic releasers ER, for overcurrents protection; in Figure $5 \mathrm{~b}$ is given the circuit breaker equipped with uVR releaser orthogonal controlled.

The breaking can be realised with adjustable delay that can be made depending by the fault seriousness. The secondary windings of the current transformers can supply the coils of orthogonal control independently or in star-star scheme.

\section{Conclusions:}

The authors propose a sensor actuator system, controlled by orthogonal magnetic field, which may be applied for all type of circuit breakers. The principle of proposed system consists of minimal voltage breaking systems with orthogonal magnetization.

The paper presents the control's principles of an electromagnetic device through orthogonal magnetisation (CROMAG) and it analysis the behaviour of a sensor-actuator to realises the protection function at the LV circuit breaker. 


\section{References:}

[1] Savin Gh., Rosman H., Circuite electrice neliniare si parametrice. Ed. Tehnica, Buc., 1973.

[2] Baraboi A., Releu static ferorezonant de tensiune sau curent. Patent RO 69826 (1978).

[3] Baraboi A., Triplor de frecventa monofazat cu bobina neliniara cu miez magnetizat pe directii ortogonale. Patent RO 70637 (1978).

[4] Baraboi A., Adam M., Leonte P., Emploi du réacteur commandé orthogonalement pour le traitement du neutre dans les intallations moyenne tension. Bul. Inst. Polit. Iasi, XLI (XLV), 1-2, s. III, 65 (1995).

[5] Baraboi A., Les caractéristiques de la bobine nonlinéaire à noyau magnétisé orthogonalement. Bul. Inst. Polit. Iasi, XLI (XLV), 3-4, s. III, 85 (1995).

[6] Baraboi A., L'utilisation de la méthode de la convolution complexe pour la détermination des solutions périodiques de régime forcé des équations différentielles nonlinéaires de second ordre, dans le cas de la résonance. Bul. Inst. Polit. Iasi, XXIV(XXVIII), 3-4, s. III, 29 (1978).

[7] Carlsson L., Persson A., Jonsson T., Liss G., Ebjörklund P., New concept in HDVC converter station design. CIGRE Report 14-102 (1996).

[8] Stănciulescu F., Analiza şi simularea sistemelor neliniare. Ed. Acad. R.S.R., Bucuresti, 1974.

[9] Leonte P., Baraboi A., Adam M., Magnetizarea in campuri ortogonale. Ed. Spectrum, Iasi, 1998.

[10] Baraboi A., Adam M., Pancu C., Buhaescu R., The Analyse and EMTP Simulation of an AC Tuned Filter. EPQU 2003, Cracow, Poland, (2003).

[11] Dorojko L. I., Libkind M. C., Reaktori s poperecinim podmagnicivaniem. Izd. Energhiia, Moskva, 1977.

[12] Leonte P., Baraboi A., Adam M., Dispozitiv electromagnetic de protectie. Patent RO 108509 B1(1994). 